\title{
Association between vitamin D insufficiency and tuberculosis in a vietnamese population
}

\author{
Lan T Ho-Pham ${ }^{1,2^{*}}$, Nguyen D Nguyen ${ }^{5,7}$, Tong T Nguyen ${ }^{3}$, Dung H Nguyen ${ }^{4}$, Phuong K Bui ${ }^{4}$, Vien N Nguyen ${ }^{4}$, \\ Tuan $\vee$ Nguyen ${ }^{5,6,7}$
}

\begin{abstract}
Background: Recent in vitro evidence suggests a link between vitamin D status and the risk of tuberculosis (TB). This study sought to examine the association between vitamin D status, parathyroid hormone (PTH) and the risk of TB in a Vietnamese population.

Methods: The study was designed as a matched case-control study, which involved 166 TB patients (113 men and 53 women), who were age-and-sex matched with 219 controls (113 men and 106 women). The average age of men and women was 49 and 50, respectively. TB was diagnosed by the presence of acid-fast bacilli on smears from sputum, and the isolation of M. tuberculosis. All patients were hospitalized for treatment in a TB specialist hospital. Controls were randomly drawn from the general community within the Ho Chi Minh, Vietnam. 25-hydroxyvitamin $\mathrm{D}[25(\mathrm{OH}) \mathrm{D}]$ and PTH was measured prior to treatment by an electrochemiluminescence immunoassay (ECLIA) on a Roche Elecsys. A serum level of 25(OH)D below $30 \mathrm{ng} / \mathrm{mL}$ was deemed to be vitamin $D$ insufficient.
\end{abstract}

Results: The prevalence of vitamin D insufficiency was $35.4 \%$ in men with TB and $19.5 \%$ in controls $(P=0.01)$. In women, there were no significant differences in serum 25(OH)D and serum PTH levels between TB patients and controls. The prevalence of vitamin D insufficiency in women with TB (45.3\%) was not significantly different from those without TB (47.6\%; $P=0.91)$. However, in both genders, serum calcium levels in TB patients were significantly lower than in non-TB individuals. Smoking (odds ratio [OR] 1.25; 95\% confidence interval [CI] 1.10 14.7), reduced 25(OH)D (OR per standard deviation [SD]: 1.14; 95\% Cl 1.07 - 10.7) and increased PTH (OR per SD $1.13 ; 95 \% \mathrm{Cl} 1.05$ - 10.4) were independently associated with increased risk of TB in men.

Conclusion: These results suggest that vitamin $D$ insufficiency was a risk factor for tuberculosis in men, but not in women. However, it remains to be established whether the association is a causal relationship.

\section{Background}

Contrary to popular belief, tuberculosis (TB) is still an on-going and important public health problem in the world. In the year 2008 alone, there were 9.4 million new cases of TB worldwide [1]. Moreover, according to the World Health Organization, at present, one-third of the world's population is infected with TB; of which, $34 \%$ are from Southeast Asian countries [2]. In Vietnam, a Southeast Asian country, TB has historically been a public health concern, due to a high prevalence and incidence in the general population. Recent statistics

\footnotetext{
* Correspondence: thuclanhopham@pnt.edu.vn

'Department of Internal Medicine, Pham Ngoc Thach University of Medicine,

Thanh Thai Street, District 10, Ho Chi Minh City, Vietnam

Full list of author information is available at the end of the article
}

indicated that during 1997-2004 there were $\sim 48,500$ cases of TB (or 70 per 100,000 population), and the incidence increased by around $0.2 \%$ per year, which occurred mainly in rural areas [3]. However, it is not clear why the incidence of TB in Vietnam has been on the rise in recent years.

In recent years, several lines of evidence suggest a link between vitamin $D$ and TB [4-7]. The active form of vitamin $\mathrm{D}(1,25(\mathrm{OH}) 2 \mathrm{D} 3)$ has been shown to inhibit growth of Mycobacterium tuberculosis (M. tuberculosis) through stimulating cell-mediated immunity and activating monocytes [6]. Studies in Gujarati Asians living in the UK found that lower levels of $25(\mathrm{OH}) \mathrm{D}$ were associated with an increased risk of pulmonary TB [8]. However, a study in Indonesia found no significant difference in

\section{() Biomed Central}


25(OH)D levels between TB and non-TB individuals [9]. Nonetheless, a recent systematic review and meta-analysis suggested that individuals with TB had lower levels of $25(\mathrm{OH}) \mathrm{D}$ than non-TB individuals [10]. The conclusion is, however, not definite because the association could be confounded by lifestyle factors and sunlight exposure which were not considered in the analysis.

While the association between vitamin $\mathrm{D}$ and TB has been studied in many Asian communities in Western countries, few studies have been done in Asian populations. In Vietnam, a tropical country, we have recently shown that the prevalence of vitamin D insufficiency in Vietnam is high [11]. Given the biologic link between vitamin $D$ and immunity, we hypothesized that TB patients had lower serum levels of vitamin $D$ than healthy individuals. This study was designed to test the hypothesis by examining vitamin $\mathrm{D}$ status and parathyroid hormone in the Vietnamese population.

\section{Methods}

\section{Study design and subjects}

The study setting was Ho Chi Minh City, Vietnam. The City is located at $10^{\circ} 45^{\prime} \mathrm{N}, 106^{\circ} 40^{\prime} \mathrm{E}$ in the southeastern region of Vietnam. The City, being close to the sea, has a tropical climate, with an average humidity of $75 \%$. There are only two distinct seasons: the rainy season, with an average rainfall of about 1,800 millimetres annually (about 150 rainy days per year), usually begins in May and ends in late November; the dry season lasts from December to April. The average temperature is $28^{\circ} \mathrm{C}\left(82^{\circ} \mathrm{F}\right)$, the highest temperature sometimes reaches $39^{\circ} \mathrm{C}\left(102^{\circ} \mathrm{F}\right)$ around noon in late April, while the lowest may fall below $16^{\circ} \mathrm{C}\left(61^{\circ} \mathrm{F}\right)$ in the early mornings of late December. The present study was taken place between April and May 2009.

The research protocol and procedures were approved by the Medical Research Committees of the People's Hospital 115 and Pham Ngoc Thach University of Medicine. All participants were provided with full information about the study's purpose and gave informed consent to participate in the study, according to the principles of medical ethics of the World Health Organization.

The study was designed as a case-control investigation, in which each case of TB was matched with 1 (for men) or 2 controls (for women), with the matching variables being age and sex. The matching ratio 1:2 for women was done to ensure the adequate of sample size for detecting an association between vitamin D and TB. The tolerance limit of age was 1 year. We used the "greedy matching algorithm" (which has been implemented in a SAS macro by Mayo Clinic) for matching data [12]. The cases were recruited from Pham Ngoc Thach Hospital (Ho Chi Minh City), which is a tertiary teaching hospital specializing in TB treatment. The data collection was undertaken as part of the National
Tuberculosis Program. During the period, all patients admitted to the Hospital and diagnosed with TB, prior to commencement of anti-TB treatment, were invited to participate in the study.

TB was ascertained according to a standard procedure, in which there was a presence of acid-fast bacilli (AFB) on smears from sputum, and the isolation of $M$. tuberculosis on culture. A definitive diagnosis of TB was made when patients met one of following criteria: (a) at least two positive AFB smears from two different sputum smears; (b) one positive AFB smear and positive culture; and (c) one positive AFB smear and typical result of lung TB infection on chest $\mathrm{X}$-ray. AFB was assessed using either fluorescence microscopy (auramine-rhodamine staining) or Ziehl-Neelsen staining method. Sputum must contain 5,000 to 10,000 bacilli/ $\mathrm{mL}$ to be considered positive.

The control group was randomly recruited from various districts within the Ho Chi Minh City from another study on vitamin D status in an urban population in Vietnam, in which study procedures have been described elsewhere [11]. Briefly, we approached community organizations, including churches and temples, and obtained the list of members, and then randomly selected individuals aged 18 or above. We sent a letter of invitation to the selected individuals. Participants were excluded from the study if they had diseases deemed to affect to vitamin D metabolism such as malabsorption syndrome, renal failure. In addition, individuals with prolonged immobility (over 2 months) were not recruited to the study. The recruitment of cases and controls was taken place at approximately the same time.

\section{Measurement of vitamin D}

Prior to commencing TB treatment, fasting serum was obtained for total calcium, creatinine, liver enzymes, and parathyroid hormone (PTH) and 25-hydroxyvitamin D [25(OH)D]. Concentration of $25(\mathrm{OH}) \mathrm{D}$ and PTH in serum was measured by electrochemiluminescence immunoassay (ECLIA) on a Roche Elecsys 10100/201 system (Roche Diagnosis Elecsys). This method can measure the concentration of $25(\mathrm{OH}) \mathrm{D}$ in the range of 4-100 $\mathrm{ng} / \mathrm{ml}(10-250 \mathrm{nmol} / \mathrm{L})$, and PTH in the range $1.2-500 \mathrm{pg} / \mathrm{ml}(0.127-530 \mathrm{pmol} / \mathrm{L})$. The sensitivity of the assay is $1.5 \mathrm{ng} / \mathrm{ml}$ with an intraassay $\mathrm{CV}$ of $5.6 \%$ at 15.9 $\mathrm{ng} / \mathrm{ml}$ and $11.6 \%$ at $58.9 \mathrm{ng} / \mathrm{ml}$. The inter-assay CV at these two levels was 9 and $\sim 12 \%$, respectively.

\section{Data collection}

A questionnaire relating to anthropometry, clinical history, lifestyle, physical activity, dietary habit, fracture and falls, were developed and used in the data collection. The questionnaire collected anthropometric data 
such as age, height and weight. Age was calculated from the date of birth to the date of interview. Height without shoes (in centimeters) was measured to the nearest 0.1 $\mathrm{cm}$ by a wall-mounted stadiometer. Weight, without shoes or clothing, was measured (to the nearest $0.1 \mathrm{~kg}$ ) on an electronic scale. Body mass index (BMI) was then derived as the ratio of weight $(\mathrm{kg})$ over height squared (in $\mathrm{m}^{2}$ ).

Each participant was asked to provide information on current and past smoking habits. This was quantified in terms of the number of pack-years consumed in each ten-year interval age group. Alcohol intake in average numbers of standard drinks per day, present as well as within the last 5 years, was obtained.

\section{Statistical analysis}

Circulating vitamin D levels were classified into four groups according to the following criteria: those undetectable $(<15 \mathrm{ng} / \mathrm{mL})$, those deficient $(<20 \mathrm{ng} / \mathrm{mL})$, those insufficient $(<30 \mathrm{ng} / \mathrm{mL})$, and those sufficient $(\geq$ $30 \mathrm{ng} / \mathrm{mL}$ ). The primary purpose of analysis was to assess the association between vitamin $\mathrm{D}$ status and the risk of TB. The main statistical model was the logistic regression analysis, in which TB status was considered the primary outcome. Circulating vitamin D level was treated as a predictor. Clinical factors and lifestyle factors were considered as covariates. The association between $25(\mathrm{OH}) \mathrm{D}$ and $\mathrm{TB}$ was expressed as odds ratio and $95 \%$ confidence interval. The $\mathrm{R}$ program was used for the statistical analysis [13].

\section{Results}

The study included 166 patients (113 men and 53 women) with TB, and 219 controls (113 men and 106 women). The average age of men and women was 49 and 50, respectively. By design, there was no significant difference in age between TB and controls. As expected, men and women with TB had lower body weight than controls. About $78 \%$ of men with TB were smokers, and this prevalence was significantly higher than in controls $(61 \%, P=0.007)$. However, in women, there was no significant difference in the prevalence of smoking between TB patients and controls $(P=0.99)$. In women, the prevalence of alcohol use was $7.5 \%$, which was significantly higher than in controls $(P=0.01)$. In men, although the prevalence of alcohol use in TB patients was higher than in those without TB (64\% vs $59 \%)$, the difference was not statistically significant $(P=0.44)$.

In men, serum levels of $25(\mathrm{OH}) \mathrm{D}$ were lower (by $10 \%$ ) and serum levels of PTH were higher (by 20\%) in patients with TB than in controls. In women, there were no significant differences in 25(OH)D and PTH between TB patients and controls. However, in both genders,
Table 1 Clinical and demographic characteristics of study participants

\begin{tabular}{|c|c|c|c|c|}
\hline Variable & Controls & Tuberculosis & $\begin{array}{l}\mathrm{MD}(95 \% \\
\mathrm{Cl})\end{array}$ & $\begin{array}{c}\mathrm{P}- \\
\text { value }\end{array}$ \\
\hline \multicolumn{5}{|l|}{ Women } \\
\hline $\mathrm{N}$ & 106 & 53 & & \\
\hline Age (yr) & $49(20)$ & $50(20)$ & $\begin{array}{l}-0.7(-7.4 \\
5.9)\end{array}$ & 0.831 \\
\hline Height (cm) & 153(6) & $154(4)$ & $\begin{array}{c}-1.4(-3.1 \\
0.4)\end{array}$ & 0.118 \\
\hline Weight (kg) & $51(7)$ & $43(6)$ & $\begin{array}{l}7.7(5.4 \\
10.0)\end{array}$ & $<.001$ \\
\hline $\log [25(\mathrm{OH}) \mathrm{D}, \mathrm{ng} / \mathrm{mL}]$ & $\begin{array}{l}3.39 \\
(0.18)\end{array}$ & $3.40(0.24)$ & $\begin{array}{c}-0.01(-0.08 \\
0.05)\end{array}$ & 0.706 \\
\hline $\log [\mathrm{PTH}, \mathrm{pg} / \mathrm{mL}]$ & $\begin{array}{l}3.47 \\
(0.39)\end{array}$ & $3.40(0.65)$ & $\begin{array}{l}0.07(-0.10 \\
0.23)\end{array}$ & 0.430 \\
\hline Serum calcium & $\begin{array}{l}2.35 \\
(0.26)\end{array}$ & $2.11(0.38)$ & $\begin{array}{l}0.24(0.14 \\
0.35)\end{array}$ & $<.001$ \\
\hline $\begin{array}{l}\text { Use of corticosteroid ( } n \text {; } \\
\%)\end{array}$ & 14(13.21) & $6(11.32)$ & & 0.735 \\
\hline Use of alcohol (n; \%) & 0 & $4(7.55)$ & & 0.011 \\
\hline Ever smoking (n; \%) & $1(0.94)$ & $1(1.89)$ & & 1.000 \\
\hline \multicolumn{5}{|l|}{ Men } \\
\hline $\mathrm{N}$ & 113 & 113 & & \\
\hline Age (yr) & $49(16)$ & $50(20)$ & $\begin{array}{c}-0.1(-4.2 \\
4.0)\end{array}$ & 0.949 \\
\hline Height (cm) & 163(6) & $154(4)$ & $\begin{array}{l}-2.1(-3.6 \\
-0.5)\end{array}$ & 0.009 \\
\hline Weight (kg) & $61(10)$ & $43(6)$ & $\begin{array}{l}13.1(10.7 \\
15.5)\end{array}$ & $<.001$ \\
\hline $\log [25(\mathrm{OH}) \mathrm{D}, \mathrm{ng} / \mathrm{mL}]$ & $\begin{array}{l}3.60 \\
(0.26)\end{array}$ & $3.49(0.24)$ & $\begin{array}{l}0.10(0.04 \\
0.17)\end{array}$ & 0.003 \\
\hline $\log [\mathrm{PTH}, \mathrm{pg} / \mathrm{mL}]$ & $\begin{array}{l}3.38 \\
(0.38)\end{array}$ & $3.40(0.65)$ & $\begin{array}{l}0.23(0.11 \\
0.35)\end{array}$ & $<0.001$ \\
\hline Serum calcium & $\begin{array}{l}2.34 \\
(0.30)\end{array}$ & $2.11(0.38)$ & $\begin{array}{l}0.28(0.19 \\
0.36)\end{array}$ & $<.001$ \\
\hline $\begin{array}{l}\text { Use of corticosteroid ( } n \text {; } \\
\%)\end{array}$ & $7(6.19)$ & $9(8.04)$ & & 0.591 \\
\hline Use of alcohol (n; \%) & $67(59.29)$ & $72(64.29)$ & & 0.441 \\
\hline Ever smoking $(n ; \%)$ & 69(61.06) & 87(77.68) & & 0.007 \\
\hline
\end{tabular}

Values are mean (standard deviation), unless otherwise specified $M D$, mean difference.

serum calcium levels in TB patients were significantly lower than in non-TB individuals (Table 1 ).

Using the criteria of $25(\mathrm{OH}) \mathrm{D}<30 \mathrm{ng} / \mathrm{mL}$, the prevalence of vitamin D insufficiency was $35.4 \%$ in men with $\mathrm{TB}$, and this prevalence was significantly higher than controls $(19.5 \%, P=0.01$; Figure 1$)$. Using the criteria of $25(\mathrm{OH}) \mathrm{D}<20 \mathrm{ng} / \mathrm{mL}$, the prevalence of vitamin D deficiency was $13.3 \%$ in men with $\mathrm{TB},>2$-fold higher than in men without TB $(5.3 \%, P=0.07)$. However, in women, there was no significant difference in vitamin $\mathrm{D}$ insufficiency ( $45 \%$ in TB vs $48 \%$ in non-TB; Figure 2 ) or vitamin deficiency ( $21 \%$ vs $19 \%$ ) between TB patients and non-TB individuals. (Table 2). 


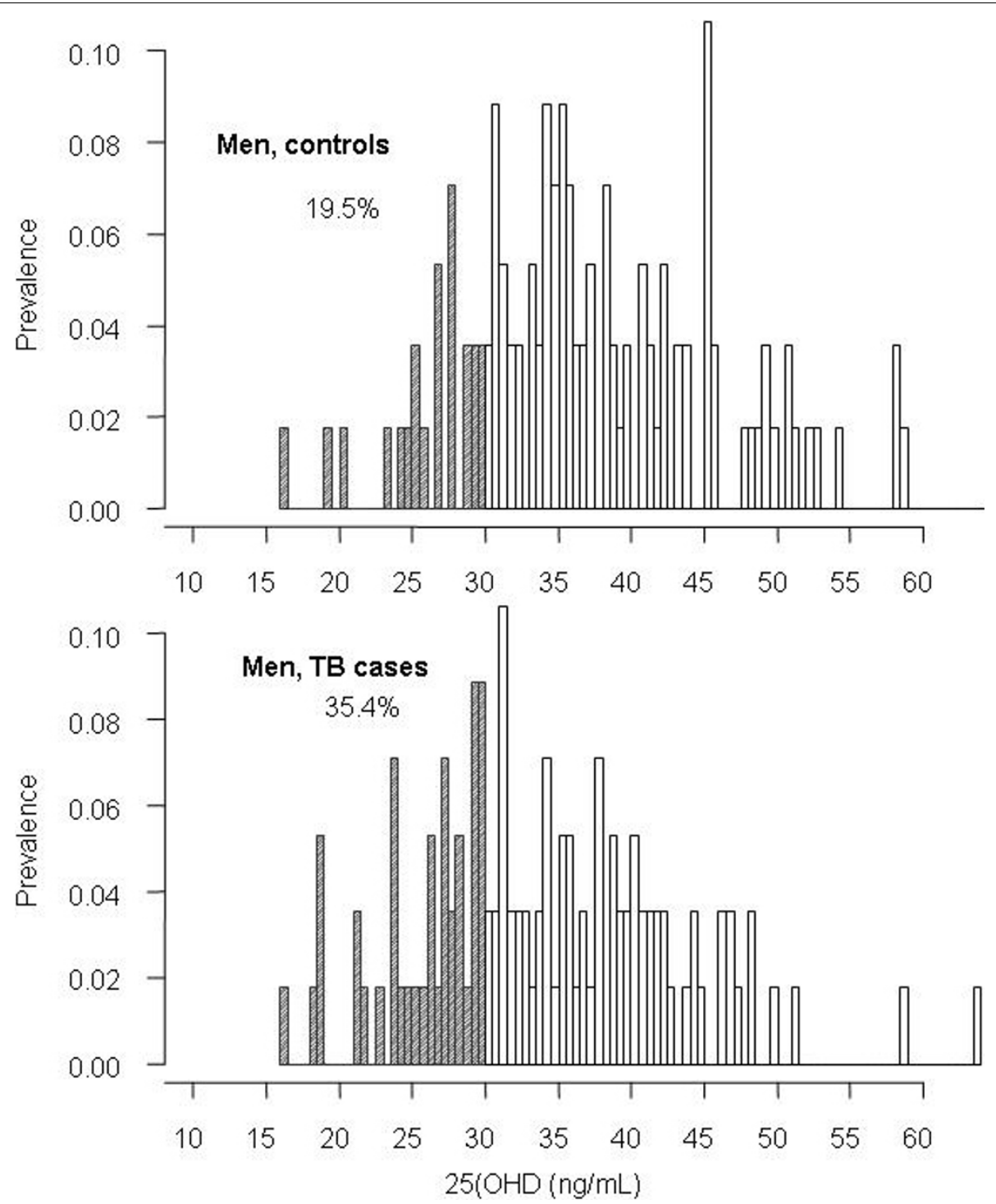

Figure 1 Prevalence of vitamin D insufficiency $(25(\mathrm{OH}) \mathrm{D}<30 \mathrm{ng} / \mathrm{mL}$ ) in controls (upper panel) and in cases with tuberculosis (lower panel), men.

In univariate logistic regression analysis, lower body weight and lower serum levels of calcium were each associated with increased risk of TB in women. However, in men, several risk factors were identified: smoking, reduced height, weight, $25(\mathrm{OH}) \mathrm{D}$, and calcium, and increased PTH (Table 3). In the multiple logistic regression model, smoking, reduced $25(\mathrm{OH}) \mathrm{D}$ and increased PTH were independently associated with increased risk of TB in men. None of these factors was associated with TB risk in women (Table 4).

\section{Discussion}

Although several lines of in-vitro evidence suggest a link between vitamin $\mathrm{D}$ and immunity, the in-vivo association between vitamin $\mathrm{D}$ status and tuberculosis is still a contentious issue. In this study we found that vitamin D insufficiency, as assessed by $25(\mathrm{OHD})$, was a risk factor for TB in men, but not in women. This finding adds to the growing evidence that vitamin D plays a role in the regulation of $M$. tuberculosis.

The possible association between vitamin $\mathrm{D}$ and tuberculosis was first reported more than 20 years ago [14], but subsequent studies have yielded conflicting findings. A number of studies in Gujarati Indian [8], Indian, Pakistani, Somali, Afghan, Sri Lankan and African residents in London [15], and African immigrants living in Australia [16] all have shown that tuberculosis had lower levels of $25(\mathrm{OH}) \mathrm{D}$ and higher prevalence of vitamin $\mathrm{D}$ deficiency than non-TB individuals. Other studies in Kenya [17] and West Africa [18] have also 

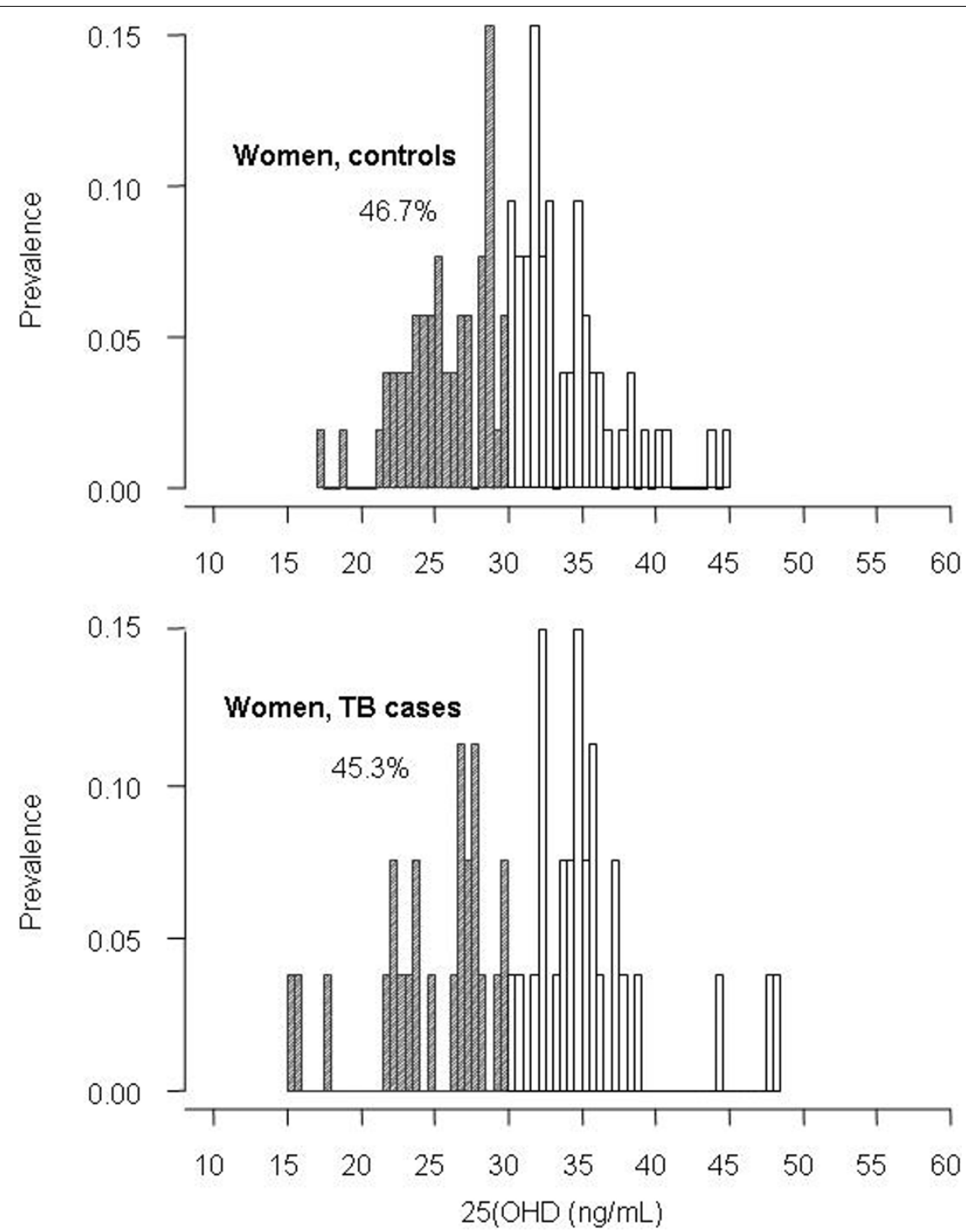

Figure 2 Prevalence of vitamin $D$ insufficiency $(25(\mathrm{OH}) \mathrm{D}<30 \mathrm{ng} / \mathrm{mL}$ ) in controls (upper panel) and in cases with tuberculosis (lower panel), women.

Table 2 Prevalence of hypovitaminosis $D$ in tuberculosis and control by various $25(\mathrm{OH}) \mathrm{D}$ cut-off values

\begin{tabular}{lccc}
\hline $\mathbf{2 5}(\mathbf{O H D})$ levels $\mathbf{( n g} / \mathbf{m L})$ & Controls & Tuberculosis & P-value \\
\hline Women $(\mathrm{n})$ & 106 & 53 & \\
$<20$ & $2(1.9)$ & $3(5.7)$ & 0.428 \\
$<25$ & $20(19.1)$ & $11(20.8)$ & 0.966 \\
$<30$ & $50(47.6)$ & $24(45.3)$ & 0.913 \\
$<50$ & $(100.0)$ & $(100.0)$ & \\
\hline Men $(\mathrm{n})$ & 113 & 113 & \\
$<20$ & $2(1.8)$ & $5(4.4)$ & 0.442 \\
$<25$ & $6(5.3)$ & $15(13.3)$ & 0.067 \\
$<30$ & $22(19.5)$ & $40(35.4)$ & 0.011 \\
$<50$ & $102(90.3)$ & $110(97.4)$ & 0.053 \\
\hline
\end{tabular}

Number in bracket is percentage of group-specific total. reported that TB patients had lower $25(\mathrm{OH}) \mathrm{D}$ levels compared to non-TB individuals. However, there was no significant difference in $25(\mathrm{OH}) \mathrm{D}$ levels between TB patients and controls in Indonesia [9] and Hong Kong [19]. Nevertheless, a recent meta-analysis concluded that TB patients had about 0.70 standard deviation (95\% CI $0.42,0.93)$ lower $25(\mathrm{OH}) \mathrm{D}$ concentration than non-TB individuals [10]. In our study the effect size (in men) was 0.42 , which was in the lower range of the effect size found in the meta-analysis. Thus, overall, our finding is broadly consistent with most previous studies.

The observation that PTH was raised in TB patients is probably not surprising, given the inverse relationship between PTH and 25(OH)D [20,21]. However, in this study we found that both reduced $25(\mathrm{OH}) \mathrm{D}$ levels and 
Table 3 Risk factors for tuberculosis, univariate analysis

\begin{tabular}{|c|c|c|c|}
\hline & Unit of & Women & Men \\
\hline & & OR $(95 \% \mathrm{Cl})$ & OR $(95 \% \mathrm{Cl})$ \\
\hline Age $(y)^{*}$ & +10 & $1.00(0.97,7.19)$ & $1.00(0.96,7.13)$ \\
\hline Height (cm) & +5 & $1.06(0.99,8.41)$ & $\begin{array}{c}1.07(1.02 \\
8.84)\end{array}$ \\
\hline Weight & -5 & $\begin{array}{c}1.15(1.10, \\
11.00)\end{array}$ & $\begin{array}{c}1.14(1.11, \\
10.59)\end{array}$ \\
\hline $\begin{array}{l}25(\mathrm{OH}) \mathrm{D}(\mathrm{ng} / \\
\mathrm{mL})\end{array}$ & -5 & $0.98(0.92,6.61)$ & $\begin{array}{c}1.10(1.03 \\
9.56)\end{array}$ \\
\hline PTH (ng/L) & -15 & $0.98(0.91,6.60)$ & $\begin{array}{c}1.11(1.03 \\
9.81)\end{array}$ \\
\hline Serum calcium & -0.3 & $\begin{array}{c}1.16(1.09, \\
11.36)\end{array}$ & $\begin{array}{c}1.20(1.14 \\
12.61)\end{array}$ \\
\hline $\begin{array}{l}\text { Corticosteroid } \\
\text { use }\end{array}$ & yes & $0.96(0.77,6.35)$ & $1.07(0.83,8.77)$ \\
\hline Alcohol use & yes & $1.98(1.25,96.32)$ & $1.05(0.92,8.33)$ \\
\hline Smoking & yes & $1.18(0.61,12.05)$ & $\begin{array}{c}1.22(1.06 \\
13.17)\end{array}$ \\
\hline
\end{tabular}

* Cases and controls were matched by age.

increased PTH levels were independently associated with an increased risk of TB, suggest that PTH may have prognostic value for the assessment of TB risk. We also found that in both genders, serum levels of calcium was lower in TB patients than in controls. However, it should be noted that in our study we did not measure albumin, and uncorrected-for-albumin calcium levels could be driven by albumin levels which are known to be lower in TB patients. A previous study in African population suggested that $\mathrm{TB}$ patients had higher serum levels of calcium [17]. This is again consistent with the physiologic understanding that the vitamin $\mathrm{D}$ hormone

Table 4 Risk factors for tuberculosis, multivariable analysis

\begin{tabular}{|c|c|c|c|}
\hline & Unit of & Women & Men \\
\hline & & OR $(95 \% \mathrm{Cl})$ & OR $(95 \% \mathrm{Cl})$ \\
\hline \multicolumn{4}{|l|}{ Model 1} \\
\hline Weight (kg) & -5 & $\begin{array}{c}\text { 1.15(1.11 } \\
11.08)\end{array}$ & $1.13(1.10,10.3)$ \\
\hline $\begin{array}{l}25(\mathrm{OH}) \mathrm{D}(\mathrm{ng} / \\
\mathrm{mL})\end{array}$ & $-1 S D^{*}$ & $0.98(0.93,6.74)$ & $1.07(1.01,8.52)$ \\
\hline PTH (pg/mL) & -15 & $0.96(0.90,6.30)$ & $1.10(1.03,9.53)$ \\
\hline Smoking & yes & $\begin{array}{c}1.15(0.62 \\
10.97)\end{array}$ & $\begin{array}{c}\text { 1.16(1.04, } \\
11.40)\end{array}$ \\
\hline \multicolumn{4}{|l|}{ Model 2} \\
\hline $\begin{array}{l}25(\mathrm{OH}) \mathrm{D} \text { (ng/ } \\
\mathrm{mL})\end{array}$ & $-1 S D^{*}$ & $0.97(0.91,6.55)$ & $\begin{array}{c}1.14(1.07 \\
10.70)\end{array}$ \\
\hline PTH (pg/mL) & -15 & $0.97(0.91,6.58)$ & $\begin{array}{c}1.13(1.05, \\
10.42)\end{array}$ \\
\hline Smoking & yes & $1.08(0.54,9.10)$ & $\begin{array}{c}1.25(1.10 \\
14.67)\end{array}$ \\
\hline
\end{tabular}

*1SD $(\mathrm{ng} / \mathrm{mL}), 5$ in women and 10 in men. system and parathyroid hormone are the principal regulators of serum concentrations of calcium [21]. However, the finding raises the question that TB patients may be at risk of increased bone loss and osteoporosis.

The observation of low 25(OH)D levels in TB patients could be due to nutritional factors, however, this is unlikely. It is well-known that most (90\%) of vitamin D is synthesized in the skin under the influence of ultraviolet sunlight of the sun, and only $10 \%$ of vitamin D is obtained from food, mainly salmon, cod fish, and dairy products. In this study, we did not assess dietary calcium intake, but typical Vietnamese diets in general contain virtually very little salt water fishes (such as cod fish and salmon) and little dairy and thus have low calcium [22]. In a previous population based study, we have shown that approximately $45 \%$ women and $20 \%$ men were vitamin D insufficient. Thus, nutritional factors are unlikely to cause the high prevalence of low vitamin $\mathrm{D}$ in TB patients.

While low 25(OH)D and calcium levels in TB patients could be a consequence of the disease, it is highly possible that vitamin $\mathrm{D}$ is an antecedent risk factors for TB. The relationship between vitamin $\mathrm{D}$ and tuberculosis may be mediated through two mechanisms: increased production of cathelicidin and enhancement of macrophage ability. $1,25(\mathrm{OH}) 2 \mathrm{D}$, the active form of vitamin $\mathrm{D}$, may enhance the production of LL-37, one of the class of defensins-antimicrobial peptides of the cathelicidin family, culminating in TB destruction $[6,23]$. Furthermore, vitamin $\mathrm{D}$ also restricts intracellular growth of $\mathrm{TB}$ via enhancement of macrophage ability. Avoidance of phago-lysosome fusion within the macrophage constitutes a key survival mechanism of TB. The ability of mycobacteria to hinder phagosomal progression, a condition known as phagosome maturation arrest [24], is partly achieved via its retention of the host's tryptophanaspartate-containing coat protein (TACO/coronin-1) [25]. Taken together, these data seem to suggest that low vitamin D status is an antecedent risk factor for TB.

The sex-specific association between vitamin $\mathrm{D}$ and TB is a notable finding, which deserves some remarks. We found the association between vitamin D status and the risk of TB in men, not in women. This finding is actually consistent with a previous study in West African population, in which the vitamin D - TB association was only observed in men, not in women [18]. In that study [18], women with TB appeared to have lower prevalence of vitamin $D$ insufficiency than women without TB (38\% vs $41 \%)$. The underlying reason for this sexspecific association is not clear. However, men in general have higher risk of tuberculosis than women [26], and this has been attributed to the sex-related differences in social economic and health care access [26] which predispose men to a greater exposure to TB than 
women. Recently, it has been proposed that estrogen is a potential mediator that could account for the lower risk of TB in women [27]; however, this hypothesis remains to be tested in empirical studies.

The present study represents one of the largest studies of vitamin D status and TB patients in Asian populations. The study was a matched case control design, and as such, it increased the reliability of estimates of effect size. The study population was highly homogeneous, which reduced the effects of potential ethnic confounders that could compromise the estimates. Moreover, the technique of measurement of $25(\mathrm{OH}) \mathrm{D}$ was a novel Elecsys Vitamin D3 automated assay, which has been shown to be a precise method for measuring vitamin $\mathrm{D}$ over a wide reportable range in serum. Indeed, recent studies have shown that measurement of $25(\mathrm{OH}) \mathrm{D}$ by this method was highly concordant with the HPLC and liquid chromatography tandem mass spectrometry methods [28]. Nevertheless, the study has a number of potential weaknesses. Because the study was a case-control design, no causal inferences could be made for the observed association between vitamin D levels and TB. We could not measure vitamin D2 (ergocalciferol) and $1,25 \mathrm{D}$ in this study; however, the occurrence of this vitamin D ( 10\% of sera [29]) seems not to be a major problem. We did not ascertain the time of exposure to sunlight among cases and controls. However, in this study most TB patients were from rural areas, and rural men normally have higher levels of sun exposure than women. It could, therefore, be argued that the data represented an underestimate of the effect of vitamin D on TB, especially in men. The participants in the control group was sampled from an urban population; but TB patients were from both urban and rural areas, as a result, the study's finding may not be generalizable to the rural population. Moreover, we did not systematically investigate active TB in the control group, and as a result, we could not exclude the possibility of inclusion of any TB cases in this group.

The finding of high prevalence of vitamin D insufficiency in TB patients has a number of clinical implications. Vitamin D in the form of cod liver oil and sunlight exposure was once a therapy for tuberculosis prior to the Robert Koch's discovery of the etiology of this disease. The association between vitamin D insufficiency and the risk of tuberculosis suggests that supplementation of vitamin D may help prevent and reduce the severity of tuberculosis. Indeed, a recent study [27] has shown that the severity of $\mathrm{TB}$ at the end of treatment was less for patients with normal vitamin D status at baseline than for those with vitamin D insufficiency, without adverse effects. However, the vitamin D dose used in the intervention $(100,000 \mathrm{IU})$ is probably too low to warrant a clinical effect. These results taken together suggest that low vitamin $\mathrm{D}$ status in $\mathrm{TB}$ patients, whether cause or effect, might be an important determinant of treatment outcome and comorbidities.

\section{Conclusions}

In summary, vitamin D insufficiency was associated with an increased risk of tuberculosis in Vietnam, but the association was observed in men, not in women. Considering findings from previous work, and given the current epidemics of vitamin $D$ insufficiency in the world and in Vietnam, the present finding warrants further studies to determine whether vitamin D supplementation can have a role in the prevention and treatment of tuberculosis in developing countries.

\section{Acknowledgements}

The study was partially supported by a grant from the University Commission for Development (CUD) program, Belgium. We thank the following fathers for their support and help in the recruitment and providing logistic support for the study: Fr. Pham Ba Lam, Fr. Vu Minh Danh, Mr. Pham Doan Phong, Mr. Luong Thang Phat, Mr. Nguyen Cong Phu, and Mr. Tien Ngoc Tuan. We thank Dr. Le Thi Ngoc Linh, Dr. Pham Ngoc Khanh of the People's Hospital 115; and our medical students Nguyen Thi Thanh Mai, Nguyen Hai Dang, Vo thi Thuy An, Nguyen thi Thanh Thao, Mai Duy Linh, Nguyen Vu Dat, Diem Dang Khoa, and Tran Hong Bao for their assistance in the interview of participants.

\section{Author details}

'Department of Internal Medicine, Pham Ngoc Thach University of Medicine, Thanh Thai Street, District 10, Ho Chi Minh City, Vietnam. ${ }^{2}$ People's Hospital 115, Thanh Thai Street, District 10, Ho Chi Minh City, Vietnam. ${ }^{3}$ MEDIC Medical Center, 254 Hoa Hao Street, District 10, Ho Chi Minh City, Vietnam. ${ }^{4}$ Pham Ngoc Thach Hospital for Tuberculosis, 120 Hong Bang Street, District 5, Ho Chi Minh City, Vietnam. ${ }^{5}$ Osteoporosis and Bone Biology Program, Garvan Institute of Medical Research, 384 Victoria Street, Sydney, NSW 2010, Australia. ${ }^{6}$ School of Public Health and Community Medicine, University of New South Wales, Sydney, NSW 2052, Australia. ${ }^{7}$ St Vincent's Clinical School, University of New South Wales, Victoria Street, Sydney, NSW 2010, Australia.

\section{Authors' contributions}

LHP and TV conceived the study concept and designed the study; LHP, PKB and TTN carried out data collection; TTN carried out the biochemical analysis, including measurement of $25(\mathrm{OH}) \mathrm{D}$; LHP and NDN performed the statistical analysis; LHP, NDN and TVN participated in the drafting of manuscript. All authors read and approved the final manuscript.

\section{Competing interests}

All authors declare that they do not have any conflict of interest with regarding to this work. Professor T. Nguyen received honorarium for speaking and providing consultant services to MSD Vietnam Ltd, SanofiAventis, Norvatis, and Roche.

Received: 20 July 2010 Accepted: 25 October 2010 Published: 25 October 2010

\section{References}

1. WHO: Global Tuberculosis Control: $A$ short update to the 2009 report. WHO Report Geneva 2010.

2. Dye C, Scheele S, Dolin P, Pathania V, Raviglione MC: Consensus statement. Global burden of tuberculosis: estimated incidence, prevalence, and mortality by country. WHO Global Surveillance and Monitoring Project. Jama 1999, 282(7):677-686.

3. Vree M, Duong BD, Sy DN, Co NV, Borgdorff MW, Cobelens FGJ: Tuberculosis trends, Vietnam. Emerging Infectious Diseases 2007, 13(5):796-797. 
4. Chocano-Bedoya P, Ronnenberg AG: Vitamin D and tuberculosis. Nutr Rev 2009, 67(5):289-293.

5. Chan TY: Vitamin D deficiency and susceptibility to tuberculosis. Calcif Tissue Int 2000, 66(6):476-478.

6. Liu PT, Stenger S, Tang DH, Modlin RL: Cutting edge: vitamin D-mediated human antimicrobial activity against Mycobacterium tuberculosis is dependent on the induction of cathelicidin. J Immunol 2007, 179(4):2060-2063.

7. Wilkinson RJ, Lange C: Vitamin $d$ and tuberculosis: new light on a potent biologic therapy? Am J Respir Crit Care Med 2009, 179(9):740-742.

8. Wilkinson RJ, Llewelyn M, Toossi Z, Patel P, Pasvol G, Lalvani A, Wright D, Latif $M$, Davidson RN: Influence of vitamin D deficiency and vitamin D receptor polymorphisms on tuberculosis among Gujarati Asians in west London: a case-control study. Lancet 2000, 355(9204):618-621.

9. Grange JM, Davies PD, Brown RC, Woodhead JS, Kardjito T: A study of vitamin $D$ levels in Indonesian patients with untreated pulmonary tuberculosis. Tubercle 1985, 66(3):187-191.

10. Nnoaham KE, Clarke A: Low serum vitamin D levels and tuberculosis: a systematic review and meta-analysis. Int J Epidemiol 2008, 37(1):113-119.

11. Ho-Pham LT, Nguyen ND, Lai TQ, Eisman JA, Nguyen TV: Vitamin D status and parathyroid hormone in a urban population in Vietnam. Osteoporos Int 2010.

12. Bergstralh E, Kosanke J: Computerized matching of cases and controls. Technical Report Number 56 Mayo Clinic, Division of Biomedical Statistics and Informatics 1995.

13. R Development Core Team: R: A Language and Environment for Statistical Computing. URL. Vienna, Austria: R Foundation for Statistical Computing, 2.7.0 2008 [http://www.R-project.org].

14. Davies PD, Brown RC, Woodhead JS: Serum concentrations of vitamin D metabolites in untreated tuberculosis. Thorax 1985, 40(3):187-190.

15. Ustianowski A, Shaffer R, Collin S, Wilkinson RJ, Davidson RN: Prevalence and associations of vitamin $D$ deficiency in foreign-born persons with tuberculosis in London. J Infect 2005, 50(5):432-437.

16. Gibney KB, MacGregor L, Leder K, Torresi J, Marshall C, Ebeling PR, Biggs BA: Vitamin $D$ deficiency is associated with tuberculosis and latent tuberculosis infection in immigrants from sub-Saharan Africa. Clin Infect Dis 2008, 46(3):443-446.

17. Davies PD, Church HA, Brown RC, Woodhead JS: Raised serum calcium in tuberculosis patients in Africa. Eur J Respir Dis 1987, 71(5):341-344.

18. Wejse C, Olesen R, Rabna P, Kaestel P, Gustafson P, Aaby P, Andersen PL, Glerup $H$, Sodemann M: Serum 25-hydroxyvitamin D in a West African population of tuberculosis patients and unmatched healthy controls. Am J Clin Nutr 2007, 86(5):1376-1383.

19. Chan TY: Differences in vitamin D status and calcium intake: possible explanations for the regional variations in the prevalence of hypercalcemia in tuberculosis. Calcif Tissue Int 1997, 60(1):91-93.

20. Holick MF: The parathyroid hormone D-lema. J Clin Endocrinol Metab 2003 88(8):3499-3500

21. Lips P: Vitamin D physiology. Prog Biophys Mol Biol 2006, 92(1):4-8.

22. Ho-Pham LT, Nguyen PL, Le TT, Doan TA, Tran NT, Le TA, Nguyen TV: Veganism, bone mineral density, and body composition: a study in Buddhist nuns. Osteoporos Int 2009, 20:2087-2093.

23. Martineau AR, Honecker FU, Wilkinson RJ, Griffiths CJ: Vitamin D in the treatment of pulmonary tuberculosis. J Steroid Biochem Mol Biol 2007, 103(3-5):793-798.

24. Fratti RA, Chua J, Vergne I, Deretic V: Mycobacterium tuberculosis glycosylated phosphatidylinositol causes phagosome maturation arrest. Proc Natl Acad Sci USA 2003, 100(9):5437-5442.

25. Houben EN, Walburger A, Ferrari G, Nguyen L, Thompson CJ, Miess C, Vogel G, Mueller B, Pieters J: Differential expression of a virulence factor in pathogenic and non-pathogenic mycobacteria. Mol Microbiol 2009, 72(1):41-52.

26. Hamid Salim MA, Declercq E, Van Deun A, Saki KA: Gender differences in tuberculosis: a prevalence survey done in Bangladesh. Int J Tuberc Lung Dis 2004, 8(8):952-957.

27. Neyrolles O, Quintana-Murci L: Sexual inequality in tuberculosis. PLoS Med 2009, 6(12):e1000199.

28. Leino A, Turpeinen U, Koskinen P: Automated measurement of $25-\mathrm{OH}$ vitamin D3 on the Roche Modular E170 analyzer. Clin Chem 2008, 54(12):2059-2062.
29. Saenger AK, Laha TJ, Bremner DE, Sadrzadeh SM: Quantification of serum 25-hydroxyvitamin $\mathrm{D}(2)$ and $\mathrm{D}(3)$ using HPLC-tandem mass spectrometry and examination of reference intervals for diagnosis of vitamin $D$ deficiency. Am J Clin Pathol 2006, 125(6):914-920.

\section{Pre-publication history}

The pre-publication history for this paper can be accessed here: http://www.biomedcentral.com/1471-2334/10/306/prepub

doi:10.1186/1471-2334-10-306

Cite this article as: Ho-Pham et al:: Association between vitamin D insufficiency and tuberculosis in a vietnamese population. BMC Infectious Diseases 2010 10:306.

\section{Submit your next manuscript to BioMed Central and take full advantage of:}

- Convenient online submission

- Thorough peer review

- No space constraints or color figure charges

- Immediate publication on acceptance

- Inclusion in PubMed, CAS, Scopus and Google Scholar

- Research which is freely available for redistribution

Submit your manuscript at www.biomedcentral.com/submit
C) Biomed Central 